\title{
Determinants of Neonatal Mortality in Ethiopia: A Case Control Study, 2013
}

\author{
Desalegn Tsegaw Hibstu ${ }^{1}$, Tadesse Awoke Ayele ${ }^{2}$, Zelalem Birhanu Mengesha ${ }^{3}$ \\ ${ }^{1}$ Department of Mid Wife, Hossana College of Health Sciences, Hossana, Ethiopia \\ ${ }^{2}$ Department of Epidemiology and Biostatistics, Institute of Public Health, University of Gondar, Gondar, \\ Ethiopia \\ ${ }^{3}$ Department of Reproductive Health, Institute of Public Health, University of Gondar, Gondar, Ethiopia \\ Email: desuethiopia@yahoo.com, t awoke@yahoo.com, zelalem78@gmail.com
}

Received 8 July 2014; revised 12 August 2014; accepted 22 September 2014

Copyright (C) 2014 by authors and OALib.

This work is licensed under the Creative Commons Attribution International License (CC BY). http://creativecommons.org/licenses/by/4.0/

(c) †) Open Access

\begin{abstract}
Introduction: Neonatal mortality is an obstacle to the continued step down of under-five mortality and the attainment of the Millennium Development Goal four. In Ethiopia, the neonatal mortality rate is decreased from 49 in 2000 to 39 deaths per 1000 live births in 2005, remaining stable at 37 deaths per 1000 live births in 2011 accounting for about $42 \%$ of under-five mortality. The aim of the study was to identify determinants of neonatal mortality in Ethiopia. Methods: Unmatched case-control study design was used to identify determinants of neonatal mortality in Ethiopia from February to June 2013 using the 2011 EDHS data. Cases were all died neonates and controls were all survived live births born within the last five years prior to 2011 EDHS. The total sample size was 11,195 with 2239 cases and 8956 controls. Logistic regression was used to identify determinants of neonatal mortality. Odds ratios with $95 \% \mathrm{CI}$ and $\mathrm{p}$-value was computed to measure the associations between the outcome variable and the independent variables. A p-value of less than 0.05 was considered as a significant result. Result: A total of $2239(20 \%)$ cases and $8956(80 \%)$ controls were included in this study. Mothers with no education (AOR = 1.89, CI: $1.32-2.72)$, short birth interval (AOR = 2.85, CI: 2.28 - 3.56), age of mother at birth (AOR = 0.18, CI: $0.04-0.86)$, multiple birth (AOR = 5.89, CI: 4.23 - 8.20), unemployed mothers (AOR = 1.39, CI: 1.07 - 1.67), unemployed fathers $(A O R=5.50, \mathrm{CI}: 3.20$ - 9.44) and place of residence $(A O R=1.63, \mathrm{CI}: 1.42-1.87)$ were found to be determinants of neonatal mortality. Conclusion: The major determinants of neonatal mortality were maternal education, birth interval, multiple birth, and age at birth, maternal and paternal employment and place of residence. Emphasis needs to be given on women's education, access to family planning, health education on consequences of early marriage and child bearing, and creating job opportunities to improve neonatal survival.
\end{abstract}

\section{Keywords}

Neonatal Mortality, Determinants, Ethiopia 


\section{Introduction}

The neonatal period is considered to be one of the greatest dangerous periods of death in human life [1]. Over 130 million babies are born every year [2] and four million newborns die during the first 4 weeks of life each year [3]. Globally, neonatal mortality constitutes $40 \%$ of the total under-five mortality where the overall neonatal mortality rate is about 30 per 1000 live births [4].

Ninety nine percent of all children who die during the first 4 weeks of life are occurring in the least developed parts of the globe, particularly in South Asia and Sub-Saharan Africa [1] [4]. Sub-Saharan Africa, which accounts for $38 \%$ of neonatal deaths in the globe, has the highest neonatal mortality rate (34 deaths per 1000 live births in 2011). The region has shown the lowest progress in cutting the rate in the last two decades and it accounts for about one-third of under-five deaths [5].

The total population of Ethiopia was about 83 million in 2010 [6]. The total fertility rate is 4.8 per woman. The population grows with a natural increase of $2.6 \%$. Seventeen percent of the population is living in urban areas. Twenty four percent of the population comprises women of reproductive age. Thirty eight percent of women and $67 \%$ of men age 15 - 49 are literate. The infant mortality, under-five mortality and the neonatal mortality are 59, 88, and 37/1000 live births, respectively [7].

Ethiopia showed a decreasing trend in under-five mortality from 166 in the 2000 EDHS to 88 per 1000 live births in 2011 EDHS while infant mortality decreased from 97 in the 2000 EDHS survey to 59 per 1000 live births in the 2011 EDHS. Though the neonatal mortality rate showed a decrease from 49 in 2000 to 39 per 1000 live births in 2005, it remained stable at 37 deaths per 1000 in 2011 and accounted for about $42 \%$ under-five mortality [7].

Many studies had indicated that child mortality, in peculiar neonatal mortality, is closely associated with a variety of factors: poverty, place of residence and region, parental education, demographic factors like maternal age at birth and sex of child, birth order, birth weight and maternal health care services usage such as antenatal care (ANC), place of delivery and delivery assistance [8]-[11].

The 2008 United Nations Children's Fund reported on maternal, newborn, and child health indicators suggested that reducing neonatal mortality is of a great importance for making extra gains in child survival [12].

In order to decrease under-five and maternal mortality, many countries have led down strategies as their cardinal development goal as proposed by international conferences including the World Summit for Children in 1990, the United Nations Millennium Declaration [13] and Nations Special Session on Children in 2002 [14].

For countries, while designing child-mortality reduction strategies, it is fundamental to know the prevalence of neonatal mortality in order to assess needs and prepare programs that will decrease avertable child deaths more rapidly [15].

There are many troubles to take action to avert the neonatal death. One of the problems has been a lack of honest information on how many newborns are really dying since births and deaths are not always registered [16]. The other obstacle is the wrong understanding that entirely expensive, high level technology and facilitybased care are needed to reduce mortality [17] [18]. Success can be achieved in avoiding neonatal deaths in circumstances with high mortality and weak health systems through outreach and family-community care, including health education to make home-care practices better, to call for skilled care, and to ameliorate care-seeking behavior [19].

A main challenge for the effective execution of neonatal intervention activities is creating and maintaining positive linkage between families, communities and health facilities through community mobilization and health education, outreach services, referral capacity and employing existing cadres of community health workers in neonatal health [20] [21].

Despite the larger share of neonatal mortality in under-5 mortality in the recent decades in developing countries, most studies focused on infant and child mortality putting neonatal mortality on the back seat [22]. And, it is considered as an obstacle to the continued step down of under-five mortality and the attainment of the MDG4 [6], this paper had tried to identify the main determinants of neonatal mortality in Ethiopia.

In the literature review, the authors included all the factors, because all these factors were included in the 
2011 Ethiopian Demography and health Survey. As a result the authors tried to identify the determinants of neonatal mortality in Ethiopia using the after mentioned factors.

\section{Methods}

\subsection{Source Population}

All live births born within the last five years prior to the 2011 EDHS data collection period. The newborns without incomplete information in the 2011 EDHS were excluded in this study.

\subsection{Study Population}

The study population included all live births born within the last five years prior to the data collection period and included in the 2011 EDHS. The cases were all live births died within one month (before 28 days) while the controls were all survived live births born within the last five years prior to the 2011 EDHS.

Study variables: The study variables were developed based on the different literatures review and from previous study. The outcome variable is neonatal death where as the explanatory variables were socioeconomic and demographic variables (place of residence, parental employment status, paternal educational status, wealth index, maternal age at birth, and marital status) and proximal variables (sex of neonate, birth interval, and number of children, birth order, and type of birth). In this paper employment status was defined as participating/not participating to any kind of job or profession that generates income, preceding birth interval was the length of time between two successive live births and type of birth was defined as refers to the number of births given during single pregnancy.

\subsection{Sample Size Determination and Sampling Procedure}

\subsubsection{Sample Size Determination}

In the 2011 EDHS, representative samples of 17,385 eligible women were identified for individual interview. Complete interviews were conducted for 16,515, yielding a response rate of 95\%. The sample size for this specific study was drawn from all live births where the total died neonates and survived neonates were 2239 and 31,137 , respectively born within the last five years from 16,515 women prior to the survey.

In this study all cases (2239) and 8956 controls were considered since excess controls and cases were available from 2011EDHS data set. The controls were selected randomly from the SPSS data received from EDHS and became 8956.

\subsubsection{Sampling Procedure}

The 2011 EDHS used a stratified sampling procedure in two stages using the 2007 population and housing census (PHC) as a frame. Stratification was achieved by separating each region into urban and rural areas. In the first step clusters were selected from the list of census enumeration areas. The sample included 624 enumeration areas, 187 in urban and 437 in rural areas. In the second stage a complete list of households in each selected cluster was carried out, and households were selected by systematic sampling. The EDHS sampling procedure was used for this study.

\subsubsection{Data Collection Tool}

The source of data for this specific research question was the 2011EDHS conducted throughout the country in September 2010. The 2011 EDHS tool has three components: the household questionnaire, the woman's questionnaire, and the man's questionnaire. These questionnaires were adapted from model survey instruments developed for the MEASURE DHS project to reflect the population and health issues relevant to Ethiopia. The data for determinants of neonatal mortality was obtained from the birth history section of the woman's questionnaire. The variables reviewed to be important for this specific research were collected from the SPSS filled data received from measuredhs.com and these data were transferred into a new SPSS data set.

\subsubsection{Quality Control}

The quality of the data was maintained by checking its completeness, cleaning the missing values by running 
frequencies, and some of the variables were recoded like survival status of the neonates, age of the mother at birth.

\subsubsection{Data Processing and Analysis}

After data filled in SPSS by the central statistical agency was downloaded from measuredhs.com, each important variable was extracted and re-entered into SPSS version 20, some of the variables were categorized and coded, then it was analyzed using SPSS version 20.0.

Descriptive statistics (frequencies, means) were used to describe both the distal and proximal determinants.

A univariate analysis was done to identify the relationship between neonatal mortality and the potential determinants without adjusting for other explanatory variables. Then all possible determinants with p-value less or equal to 0.20 in the univariate analysis were used to admit more possible determinants. Determinants identified in the univariate analysis with neonatal mortality were entered into a multiple logistic regression model to determine their significant association simultaneously.

The final model used was found to be a valid model with Hosmer-Leme show goodness of fit with p-value greater than 0.05 which was 0.954 . Odds ratios (OR) with 95\% confidence intervals (CIs) and p-value were computed using logistic regression models to assess the relationship between neonatal mortality and each selected variable.

\section{Results}

\section{Determinants of Neonatal Mortality}

In the multiple logistic regression analysis age at birth, place of residence, maternal education, maternal and paternal employment status, birth order in the family, type of birth, and birth interval and wealth index were significantly associated with neonatal death. Paternal education, marital status and sex of neonate were not identified as determinants of neonatal mortality.

The study demonstrated that mothers who gave birth in the age group 20 - 34 years old, neonatal death was $82 \%$ (AOR $=0.18$, CI: $0.04-0.86$ ) less likely to occur in relative with those mothers who gave birth before celebrating their 20 years birthday.

Newborns living in the rural areas were 1.63 (AOR $=1.63$, CI: $1.42-1.87$ ) times more likely to die in comparison with those living in the urban areas.

Almost a 2 fold increase in neonatal death was observed if mothers did not attend any education than those who had secondary and above education (AOR $=1.89$, CI: $1.32-2.72)$.

Maternal and paternal employment status was more likely to increase neonatal death by 1.39 (AOR $=1.39$, CI: 1.07 - 1.67) and $5.50(\mathrm{AOR}=5.50$, CI: 3.20 - 9.44) times among unemployed parents than employed parents, respectively.

The study also observed that the chance of neonatal death was higher among mothers who belonged to the poor wealth index by 2.28 (AOR = 2.28, CI: 1.52 - 3.42) times compared with those with the rich wealth index.

Another important predictor was the type of birth and birth interval. The probability of neonatal death in multiple births was 5.89 (AOR = 5.89, CI: 4.23 - 8.20) times higher compared with single births. Neonates born to a birth spacing less than 36 months was 2.85 times (AOR $=2.85$, CI: 2.28 - 3.56) more likely to experience neonatal death than those born with a birth spacing of 36 months and above birth interval.

It was also observed that the chance of neonatal death was increased by 1.31times (AOR $=1.31$, CI: 1.02 1.69) among neonates living in the family with more than four children than less or equal to four children (Table $1)$.

\section{Discussion}

Infant and under-five mortality in Ethiopia has decreased continuously over the last decade, reaching 59 and 88 per 1000 live births in 2011, respectively [7]. In spite of the reduction of infant and under-five mortality, additional efforts will be required to achieve the Millennium Development Goal of reducing under-five mortality by two thirds in the year 2015 compared to its level in 1990 by cutting down neonatal mortality which has a contribution of about $42 \%$ of overall under-five mortality. Thus, this study had tried to identify the determinants of neonatal mortality in Ethiopia.

Significant association was observed concerning maternal education. It was figured out that neonatal death 
Table 1. Determinants of neonatal mortality identified in the multivariate logistic regression in Ethiopia, June 2013 (n = 11.195).

\begin{tabular}{|c|c|c|c|c|}
\hline \multirow{2}{*}{ Variables } & Died & Alive & \multirow{2}{*}{ COR (95\% CI) } & \multirow{2}{*}{ AOR (95\% CI) } \\
\hline & N (\%) & N (\%) & & \\
\hline \multicolumn{5}{|l|}{ Age at birth } \\
\hline$<20$ years & $40(1.8)$ & $115(1.2)$ & 1.00 & 1.00 \\
\hline 20 - 34 years & 155 (6.9) & $802(9.0)$ & $0.56(0.37-0.83)$ & $0.18(0.04-0.86)^{*}$ \\
\hline$>34$ years & 2044 (91.3) & 8039 (89.8) & $0.73(0.51-1.05)$ & $0.11(0.02-0.50)^{*}$ \\
\hline \multicolumn{5}{|l|}{ Residence } \\
\hline Urban & $273(12.2)$ & 1525 (17) & 1.00 & 1.00 \\
\hline Rural & 1966 (87.8) & 7431 (83) & $1.48(1.29-1.70)$ & $1.63(1.42-1.87)^{* *}$ \\
\hline \multicolumn{5}{|l|}{ Maternal employment } \\
\hline Unemployed & $1232(55)$ & $4410(49.2)$ & $1.261(1.149-1.384)$ & $1.39(1.07-1.67)^{*}$ \\
\hline Employed & $1007(45)$ & $4546(50.8)$ & 1.00 & 1.00 \\
\hline \multicolumn{5}{|l|}{ Paternal employment } \\
\hline Unemployed & 310 (13.9) & 137 (1.5) & $10.33(8.40-12.71)$ & $5.50(3.20-9.44)^{* *}$ \\
\hline Employed & 1927 (86.1) & 8798 (98.5) & 1.00 & 1.00 \\
\hline \multicolumn{5}{|l|}{ Type of birth } \\
\hline Single & $1770(79.1)$ & 8571 (95.7) & 1.00 & 1.00 \\
\hline Multiple & 469 (20.9) & 385 (4.3) & $5.90(5.11-6.81)$ & $5.89(4.23-8.20)^{* * *}$ \\
\hline \multicolumn{5}{|l|}{ Birth interval } \\
\hline$<36$ month & $902(56.2)$ & 2001 (29) & $3.14(2.81-3.51)$ & $2.85(2.28-3.56)^{* * *}$ \\
\hline$\geq 36$ month & 702 (43.8) & $4890(71)$ & 1.00 & 1.00 \\
\hline \multicolumn{5}{|l|}{ No. of children } \\
\hline$\leq 4$ & 1149 (51.3) & $4460(49.8)$ & 1.00 & 1.00 \\
\hline$>4$ & $1090(48.7)$ & $4496(50.2)$ & $0.94(0.86-1.03)$ & $1.31(1.02-1.69)^{*}$ \\
\hline \multicolumn{5}{|l|}{ Maternal education } \\
\hline No education & $1821(81.3)$ & $6917(77.2)$ & $1.79(1.30-2.47)$ & $1.89(1.32-2.72)^{* *}$ \\
\hline Primary & $374(16.7)$ & 1739 (19.4) & $1.46(1.05-2.05)$ & $1.58(1.10-2.28)^{*}$ \\
\hline Secondary and above & $44(2)$ & $300(3.4)$ & 1.00 & 1.00 \\
\hline \multicolumn{5}{|l|}{ Paternal education (x) } \\
\hline No education & $1402(51.5)$ & $5204(58.2)$ & $1.40(1.17-1.67)$ & \\
\hline Primary & 656 (29.3) & 2916 (32.6) & $1.20(0.99-1.45)$ & \\
\hline Secondary and above & $94(4.2)$ & $536(6)$ & $1.13(0.742-1.71)$ & \\
\hline \multicolumn{5}{|l|}{ Wealth index } \\
\hline Poor & $1152(51.5)$ & $4262(47.6)$ & $1.25(1.13-1.39)$ & $2.28(1.52-3.42)^{* *}$ \\
\hline Middle & 404 (18) & 1534 (17.1) & $1.22(1.06-1.40)$ & $2.21(1.43-3.41)^{*}$ \\
\hline Rich & $683(30.5)$ & 3160 (35.3) & 1.00 & 1.00 \\
\hline \multicolumn{5}{|l|}{ Marital status (x) } \\
\hline Single & $20(0.9)$ & $123(1.4)$ & 1.00 & \\
\hline Married & 2219 (99.1) & 8833 (98.6) & $0.647(0.40-1.04)$ & \\
\hline \multicolumn{5}{|l|}{ Sex (x) } \\
\hline Male & 1318 (58.9) & $4712(52.6)$ & $1.29(1.17-1.42)$ & \\
\hline Female & $921(41.1)$ & $4244(47.4)$ & 1.00 & \\
\hline
\end{tabular}

Note: ${ }^{*}$-value $<0.05,{ }^{* *}$-value $<0.001$ and it is the p-value of the multiple logistic regression output. 
was more likely to occur among mothers with no education. This finding is congruent with other study [23] [24]. This might be explained by the fact that there is no question that educated mothers can provide better care for themselves and for their neonates than those with no education or a lower level of education. Education provides better health knowledge, improves the effectiveness of health behavior and enables to take the necessary measures to prompt new born care.

The paternal employment status in this analysis was significantly associated with neonatal death. Neonatal death was less likely to occur among employed fathers than unemployed fathers. This study is in line with the finding in Indonesia [10]. This might be happened because employed fathers would have a protective effect on neonatal mortality by increasing household income and economic status of the family and as a result mother during pregnancy might get frequent health institution contact for antenatal care, delivery and immunization.

This study demonstrated that neonatal death is more likely to increase among mothers who were unemployed than employed mothers. This finding showed consistency with the results obtained in other areas [10] [25]. This might be happened because unemployed women might not have cash at hand to get better health care for themselves during pregnancy and to their newborns.

Regarding wealth index, neonatal death was less likely to occur in the richest wealth index than the poorest wealth index. This study is similar with the finding in Republic of the Sudan [26]-[28]. This is happened probably because of mothers in the rich quintile might get necessary health service during pregnancy, delivery and after delivery, and the neonates might be provided better care.

The study also revealed that the chance of neonatal death is increased among multiple births in comparison with single births. This finding was in line with a study done in developing countries [29] [30]. The higher neonatal death among multiple births might be due to biological factors such as low birth weight and complications during delivery.

In this study it was observed that neonatal death was less likely to occur among mothers who gave birth in the age group 20 - 34 years old compared to mothers below age 20 years old. This result was in line with other findings [31]-[34]. This could be explained due to the complication occurred among adolescent mothers during pregnancy and delivery, and babies born might be premature and underweight. It might be also explained as elder mothers not only own better knowledge of pregnancy and child bearing but also ready psychologically and physically compared to younger mothers that help them to take care of their newborns in a better way in this period.

The type of place of residence was also found as a determinant of neonatal death. The study found that neonatal death was more likely to increase among newborns born in the rural residence in comparison with urban areas. This finding was supported by the findings in Bangladesh, Ghana and Gambia [25] [35] [36]. This is probably because urban areas are exposed to different health care services including higher coverage with immunization and safe delivery suggesting a lower risk of experiencing neonatal mortality. And it is known that urban areas are mostly equipped with better infrastructure for health services than rural areas.

On the other hand, probably because better care provided for neonates and no competitor for food, for schooling, getting health service between those households with small number of children, in this study, it was pointed out that neonatal death was more likely to increase among households whose number of children were above four. This study was in agreement with the findings in other areas [37] [38].

With regard to birth interval, the study showed that the shorter the birth interval (below 36 months), the probability of neonatal death will be more likely to increase in relative with those whose birth interval was 36 months and above. This finding is in line with the study conducted in other areas [10] [39]-[41]. This could be linked to maternal health problems where women with short birth intervals between two pregnancies have insufficient time to restore their nutritional reserves which is thought to adversely affect fetal growth as a result of giving a narrowly spaced birth.

\section{Limitation of the Study}

Certain members of the population were underrepresented in the survey since DHS methodology uses surviving women of reproductive age as the source of information, so neonates without living mothers are excluded from the survey.

Mothers might underreport both the birth and death of a newborn (recall bias and social desirable bias) and might misreport date of birth and age at death. 


\section{Conclusions}

In general, in this study maternal education, maternal and paternal employment status, maternal age (below 20 years old), being multiple births, shorter birth interval (below 36 months), number of children greater than four, and place of residence were identified as the determinants of neonatal mortality.

Health education dissemination strategies (e.g. campaign to family planning services) on the benefits of birth spacing at least by three years, avoiding early marriage, participating in income generating activities need to be continuously done at the community and health facility level.

The FMOH needs to address short birth interval continuously to avert adolescent pregnancy and child birth through effective family planning programs as one of neonatal survival interventions. Health education strategies (like using mass Medias) need to be considered to discourage early marriage, adolescent child bearing and short birth spacing.

Programs should address areas and populations with higher neonatal mortality rates in rural areas and households with the least wealth.

The MOE needs to give emphasis on women's education to continue their educational level secondary and above.

Creating and promoting income generating mechanisms and creating job opportunities need to be considered.

And, it is also recommended that different experts of governmental and non-governmental (policy makers, planners) use this finding as an input in reducing neonatal mortality so that it will be possible to achieve the MDG4.

\section{Acknowledgements}

The DHS data for the 2011 survey were taken from the Central Statistical Agency of Ethiopia and ICF International, Calverton, Maryland, USA. The study was financially supported by Hosanna College of Health Sciences, Southern Ethiopia.

\section{Authors' Contributions}

Desalegn Tsegaw, Tadesse Awoke and Zelalem Birhanu participated from the conception to the end of this manuscript.

\section{Competing Interests}

The authors declared that there are no competing interests.

\section{References}

[1] Lawn, J.E., et al. (2005) 4 Million Neonatal Deaths: When? Where? Why? Lancet, 365, 891-900. http://dx.doi.org/10.1016/S0140-6736(05)71048-5

[2] The World Health Report (2005) Make Every Mother and Child Count. World Health Organization, Geneva.

[3] Black, R.E., et al. (2010) Global, Regional, and National Causes of Child Mortality in 2008: A Systematic Analysis. Lancet, 375, 1969-1987. http://dx.doi.org/10.1016/S0140-6736(10)60549-1

[4] Lawn, J.E., et al. (2009) Survival in Low Resource Settings-Are We Delivering? BJOG: An International Journal of Obstetrics \& Gynaecology, 116, 49-59. http://dx.doi.org/10.1111/j.1471-0528.2009.02328.x

[5] UNICEF (2012) Levels and Trends in Child Mortality: Estimates Developed by the UN Inter-Agency Group for Child Mortality Estimation. New York, USA.

[6] Bayou G. and Berhan, Y. (2012) Perinatal Mortality and Associated Risk Factors: A Case Control Study. Ethiopian Journal of Health Sciences, 22, 153-162.

[7] Central Statistical Agency (Ethiopia) and ICF International (2012) Ethiopia Demographic and Health Survey 2011. Central Statistical Agency and ICF International, Addis Ababa, Ethiopia and Calverton, Maryland, USA.

[8] Mahmood, M.A. (2002) Determinants of Neonatal and Post-Neonatal Mortality in Pakistan. The Pakistan Development Review Journal, 41, 723-744.

[9] Schell, C.M., et al. (2007) Socioeconomic Determinants of Infant Mortality: A Worldwide Study of 152 Low, Middle and High-Income Countries. Scandinavian Journal of Public Health, 35, 288-297. 
http://dx.doi.org/10.1080/14034940600979171

[10] Titaley, C.R., et al. (2008) Determinants of Neonatal Mortality in INDONESIA. BMC Public Health, 8, 232. http://dx.doi.org/10.1186/1471-2458-8-232

[11] Abuqamar, M.D., et al. (2011) The Impact of Parental Education on Infant Mortality in Gaza Strip, Palestine. Journal of Public Health and Epidemiology, 3, 28-33.

[12] Bryce, J. and Requejo, J.H. (2008) Countdown to 2015. Tracking Progression on Maternal Newborn \& Child Survival. The 2008 Report. UNICEF, New York.

[13] (2013) http://www.un.org/millennium/declaration/accessed

[14] (2013) http://www.unicef.org/specialsession/accessed

[15] World Health Organization (2006) Neonatal and Perinatal Mortality: Country, Regional and Global Estimates. Geneva.

[16] Mason, E. (2013) Newborns in Sub-Saharan Africa: How to Save These Fragile Lives. UN Chronicle. Dec 2007.

[17] MacFarlane, A.J., Johnson, A. and Mugford, M. (2006) Epidemiology of Neonatal Mortality. In: Rennie, J.M. and Roberton, N.R.C., Eds., Textbook of Neonatology, Churchill Livingstone, Edinburgh, 3-33.

[18] McKeown, T., Record, R. and Turner, R. (2007) An Interpretation of the Decline in Mortality in England and Wales during the Twentieth Century. Population Studies, 29, 391-422. http://dx.doi.org/10.1080/00324728.1975.10412707

[19] Darmstadt, G.L., Bhutta, Z.A., Cousens, S., Adam, T., Walker, N. and de Bernis, L. (2005) Evidence-Based, Cost-Effective Interventions: How Many Newborn Babies Can We Save? The Lancet, 365, 977-988. http://dx.doi.org/10.1016/S0140-6736(05)71088-6

[20] Haws, R.A., Thomas, A.L., Bhutta, Z.A. and Darmstadt, G.L. (2007) Impact of Packaged Interventions on Neonatal Health: A Review of the Evidence. Health Policy and Planning, 22, 193-215. http://dx.doi.org/10.1093/heapol/czm009

[21] Oestergaard, M.Z., Inoue, M., Yoshida, S., Mahanani, W.R., Gore, F.M., Cousens, S., et al. (2011) Neonatal Mortality Levels and Trends for 193 Countries in 2009 with Trends since 1990: A Systematic Analysis of Progress, Projections, and Priorities. PLoS Medicine, 8, e1001080. http://dx.doi.org/10.1371/journal.pmed.1001080

[22] Rajaratnam, J.K., Marcus, J.R., Flaxman, A.D., Wang, H., Levin-Rector, A., Dwyer, L., et al. (2010) Neonatal, Post Neonatal, Childhood, and under-5 Mortality for 187 Countries, 1970-2010: A Systematic Analysis of Progress towards the Millennium Development Goal 4. The Lancet, 375, 1988-2008. http://dx.doi.org/10.1007/s13312-012-0044-2

[23] Mondal, N., Hossain, K. and Ali, K. (2009) Factors Influencing Infant and Child Mortality: A Case Study of Rajshahi District, Bangladesh. Journal of Human Ecology, 26, 31-39.

[24] Upadhyay, R.P., Dwivedi, P.R., Rai, S.K., Misra, P., Kalaivani, M. and Krishnan, A. (2012) Determinants of Neonatal Mortality in Rural Haryana: Nested Case-Control Study. Indian Pediatrics, 49, 291-294. http://dx.doi.org/10.1007/s13312-012-0044-2

[25] Tachiweyika, E., Gombe, N., Shambira, G., Chadambuka, A., Mufuta, T. and Zizhou, S. (2009) Determinants of Perinatal Mortality in Marondera District, Mashonaland East Province of Zimbabwe: A Case Control Study. Pan African Medical Journal, 8, 7.

[26] Rutherford, M.E., Dockerty, J.D., Jasseh, M., Howie, S.R.C., Herbison, P., Jeffries, D.J., et al. (2009) Access to Health Care and Mortality of Children under 5 Years of Age in Gambia: A Case-Control Study. Bulletin of World Health Organization, 87, 216-224. http://dx.doi.org/10.2471/BLT.08.052175

[27] Bashir, A.O., Ibrahim, G.H., Bashier, I.A. and Adam, I. (2013) Neonatal Mortality in Sudan: Analysis of the Sudan Household Survey, 2010. BMC Public Health, 13, 287. http://dx.doi.org/10.1186/1471-2458-13-287

[28] Mendes, K.G., Olinto, M.T.A. and da Costa, J.S.D. (2006) Case-Control Study on Infant Mortality in Southern Brazil. Revista de Saúde Pública, 40, 240-248. http://dx.doi.org/10.1590/S0034-89102006000200009

[29] Awour, I., Abed, Y. and Ashour, M. (2012) Determinants and Risk Factors of Neonatal Mortality in the Gaza Strip, Occupied Palestinian Territory: A Case-Control Study. The Lancet, 380, 25-26. http://dx.doi.org/10.1016/S0140-6736(13)60206-8

[30] Hong, R., Ayad, M., Rutstein, S. and Ren, R. (2009) Childhood Mortality in Rwanda: Levels, Trends, and Differentials. Further Analysis of the Rwanda Demographic and Health Surveys 1992-2007/08. 66, 27.

[31] Chaman, R., Naieni, K.H., Golestan, B., Nabavizadeh, H. and Yunesian, M. (2009) Neonatal Mortality Risk Factors in a Rural Part of Iran: A Nested Case-Control Study. Iranian Journal of Public Health, 38, 48-52.

[32] Mahmood, M.A. (2002) Determinants of Neonatal and Post-Neonatal Mortality in Pakistan. The Pakistan Development Review, 41, 723-744.

[33] Sharma, V., Katz, J., Mullany, L.C., Khatry, S.K., LeClerq, S.C., Shrestha, S.R., et al. (2008) Young Maternal Age and the Risk of Neonatal Mortality in Rural Nepal. Archives of Pediatrics \& Adolescent Medicine, 162, 828-835. http://dx.doi.org/10.1001/archpedi.162.9.828 
[34] Kamal, S.M. (2011) What Is the Association between Maternal Age and Neonatal Mortality? Analysis of the 2007 Bangladesh Demographic and Health Survey. Asia-Pacific Journal of Public Health, Published Online. http://dx.doi.org/10.1177/1010539511428949

[35] Kamal, S.M.M. (2012) Maternal Education as a Determinant of Neonatal Mortality in Bangladesh. Journal of Health Management, 14, 269-281. http://dx.doi.org/10.1177/0972063412457509

[36] Maraga, A. and Emily, S. (2011) Risk Factors of Neonatal Mortality in Navrongo DSS in Ghana between 2001 and 2005.

[37] Amoa, A.B. (2002) A Case-Control Study of Early Neonatal Deaths at the Port Moresby General Hospital in Papua New Guinea to Determine Associated Risk Factors. Papua New Guinea Medical Journal, 45, 185-196.

[38] Susuman, A.S. (2012) Child Mortality Rate in Ethiopia. Iranian Journal of Public Health, 41, 9-19.

[39] Mahy, M. (2003) Childhood Mortality in the Developing World: A Review of Evidence from the Demographic and Health Surveys, Comparative Report, No. 4. Macro International Inc., Irvine.

[40] Upadhyay, U.D. and Setty-Venugopal, V. (2002) Birth Spacing: Three to Five Saves Lives. Johns Hopkins University Editor, Baltimore, 1-23.

[41] Akin, Y., Cömert, S., Turan, C., Ünal, O., Piçak, A., Ger, L., et al. (2010) Increasing Low Birth Weight Rates: Deliveries in a Tertiary Hospital in Istanbul. Iran Journal of Pediatrics, 20, 284-290.

\section{Abbreviations}

ANC (Antenatal Care), AOR (Adjusted Odd Ratio), COR (Crude Odd Ratio), CSA (Central Statistical Agency), DHS (Demographic Health Survey), EDHS (Ethiopian Demographic Health survey), ERB (Ethical Review Board), FMOH (Federal Ministry of Health), HSDP (Health Sector Development Program), LBW (Low Birth Weight), MDG (Millennium Development Goal), MOE(Ministry of Education), MPH(Master of Public Health), NNM (Neonatal Mortality), PHC (Population and Housing Census), SPSS (Statistical Package for Social Science), UNCEF (United Nations Children’s Fund), WHO (World Health Organization). 